Kansas State University Libraries

New Prairie Press

\title{
COMPARING THE USE OF BLOCK AND COVARIATE INFORMATION IN ANALYSIS OF VARIANCE
}

James R. Schwenke

Follow this and additional works at: https://newprairiepress.org/agstatconference

Part of the Agriculture Commons, and the Applied Statistics Commons

\section{c) (1) $\Theta$}

This work is licensed under a Creative Commons Attribution-Noncommercial-No Derivative Works 4.0 License.

\section{Recommended Citation}

Schwenke, James R. (1997). "COMPARING THE USE OF BLOCK AND COVARIATE INFORMATION IN ANALYSIS OF VARIANCE," Conference on Applied Statistics in Agriculture. https://doi.org/10.4148/ 2475-7772.1299

This is brought to you for free and open access by the Conferences at New Prairie Press. It has been accepted for inclusion in Conference on Applied Statistics in Agriculture by an authorized administrator of New Prairie Press. For more information, please contact cads@k-state.edu. 


\author{
James R. Schwenke \\ Department of statistics \\ Kansas State University
}

\title{
Abstract
}

Of primary concern in the statistical analysis of the results of an experiment is to quantify the mean response to treatment and to accurately quantify the experimentation error variance. The traditional approach to account for nuisance sources of variation or a heterogeneous population is to group or block the population (or sample) into homogeneous groups with respect to a concomitant variable. A blocking term then is included in the statistical analysis. Alternatively, concomitant variables can be used as covariate information in a statistical analysis. A statistical analysis incorporating blocks assumes that the magnitude of difference in treatment response is equal across all blocks. Covariate information is used in an analysis to describe individual differential treatment effects on response. Covariate information used in conjunction with blocks may allow for a more realistic and appropriate estimate of the experimentation error variance and, thus, a more powerful analysis.

A series of examples is presented to demonstrate the potential advantage to utilizing both block and covariate information in an analysis of variance.

\section{Introduction}

The reliability of an inference drawn from an experiment is determined by the quality of the information (data) collected during the experiment and the appropriateness of the statistical analysis. In addition to being able to quantify the mean response of a subject (experimentation unit) to treatment, another primary concern is being able to quantify the experimentation error variance associated with the observed data. The experimentation error variance is the variation in response associated with the defined experimentation unit that would be expected in repeated application of an identical treatment to different experimentation units under similar conditions. The experimentation error variance provides the ability to determine if a statistically significant treatment response has been observed. It also partly defines the limits of the population to which the statistical inference can be extended.

In order to accurately quantify the experimentation error variance, all other sources of variation not associated with experimentation error must be quantified and partitioned from the estimate of the experimentation error variance. Depending on the experimentation unit defined in the experiment, such sources of variation could include pen-to-pen variation, variation due to location, or variation due to day of the week or other concomitant variables. often, these additional sources of variation not related to experimentation error are called nuisance sources of variation. If the design and conduct of the experiment do not address all sources of variation, the statistical analysis may be less effective, or making a reliable inference may not be possible. To accurately summarize the data and quantify the experimentation 
error variance, the statistical analysis must reflect both the design and conduct of the experiment and the characteristics of the response variable.

A key component in the experimentation process is the appropriate randomization of treatments to experimentation units. Traditionally, randomization is thought of as a mechanism to help reduce or eliminate bias from the experimentation process. Randomization also provides the ability to accurately estimate not only the mean response to treatment but also the experimentation error variance by helping to control or account for nuisance sources of variation. In addition, randomization can help to maintain equality of treatment allocation among experimentation groups throughout the experiment, which helps provide more powerful analyses.

The objective of this paper is to discuss how a judicious randomization of treatments to experimentation units can maximize the information obtained from the response data and the subsequent statistical analysis. Four examples are discussed to highlight the importance of recognizing nuisance sources of variation and incorporating them into the experiment through randomization and appropriate statistical analysis.

\section{Basic Design}

Each of the following examples is based on the results of a study that was conducted to determine the effect of various levels of treatment on the weight of calves. Four treatment groups were involved in the study: a control with low, medium, and high dose levels. Ten calves were assigned through randomization to each treatment group.

The following series of examples will demonstrate the effect of two different randomization schemes on the conduct, results, and interpretation of the experiment. In addition, two statistical analysis strategies will be presented to demonstrate how differing randomization schemes can influence both the statistical analysis and interpretation of the results. Together, these examples demonstrate several possibilities for controlling or accounting for the effect of nuisance sources of variation through randomization and analysis techniques.

\section{Completely Randomized Design Structure}

In this first example, treatment was assigned to each experimentation unit (calf) in a completely random fashion, without regard to any concomitant variable or characteristic. A computer-generated randomization table was used to assign treatments to help assure an unbiased allocation, as well as equal representation among the four treatment groups. This method of randomization assumes that the calves in the study represent a sample from a homogeneous population, which is not stratified by some systematic characteristic. It also assumes that calves within the population would respond to an identical treatment in a similar manner. Thus, calf-to-calf variation in response represents experimentation error variation.

Table 1 is a summary of the completely randomized allocation of treatments to calves and the final weight observed for each calf at the end of study. Figure 1 is a graphical representation of the final weight measurements for each calf by treatment group, which appears to indicate an increasing trend in final weight with increased level of dose. A statistical analysis is 
used to determine if the apparent difference in final weight among treatment groups is significant and, thus, a repeatable response.

In this example, the experiment was conducted with a one-way treatment structure and a completely randomized design structure. Thus, the statistical analysis must incorporate both differences in final weight due to treatments and differences in final weight due to between-calf variation within a treatment group. Here, the variation in final weight among calves within the same treatment group provides the estimate of the experimentation error variance. This measures the variation in response that would be expected if no differences existed among treatment groups. If the difference in final weight associated with treatment is in excess of the experimentation error variance, a significant treatment difference is declared. The analysis of variance (ANOVA) model for this design is $\mathrm{y}_{i j}=\mu_{i}+\varepsilon_{i j}$ where $\mathrm{y}_{i j}$ denotes the final weight of calf $j$ receiving dose $i, \mu_{i}$ denotes the mean effect of dose $i$, and $\varepsilon_{i j}$ denotes random error with $\varepsilon_{i j} \sim$ iid $N\left(0, \sigma_{\varepsilon}^{2}\right)$.

Table 2 is a summary of the ANOVA using the data displayed in Table 1. The estimate of the experimentation error variance is 323.51303 with 36 degrees of freedom, given as the mean square error. The test statistic for detecting treatment differences has a value of 1.14 with a corresponding p-value of 0.3470 , which indicates that no significant treatment differences among groups can be declared. Although not relevant for this example, pairwise comparisons among the least squares means for treatment response also do not indicate any significant treatment differences $(p \geq 0.0955)$.

\section{Analysis of Covariance}

Analysis of covariance is a statistical technique useful for accommodating the effect of a concomitant variable (covariate) in the statistical analysis. The technique assumes that a linear relationship exists between the response and the concomitant variable. Analysis of covariance also allows for treatment to affect the magnitude of the relationship where, for example, the difference in final weight among treatment groups may be more dramatic in calves with heavier initial weights. The experimentation error variance is estimated after the response data are adjusted for the effect of the covariate. If the covariate has a significant effect on response, the estimate of the experimentation error variance obtained through analysis of covariance will be smaller than the estimate obtained through ANOVA techniques. Because ANOVA does not accommodate covariate effects, the reported mean square error from ANOVA is a combined estimate of both the experimentation error variance and variation in response due to the covariate. The estimate will be inflated and, thus, if used, may leave significant treatment differences undetected.

Continuing with the previous example data presented in Table 1, a potential covariate associated with final weight is initial weight of each calf prior to treatment. Table 3 is an expanded data listing showing each calf's initial weight. The final weight data are the same as given in Table 1 with the same completely randomized treatment allocation. The analysis of covariance model for this design is $y_{i j}=\mu_{i}+\beta_{i} x_{i j}+\varepsilon_{i j}$ where $y_{i j}$ denotes the final weight of calf $j$ receiving dose $i, \mu_{i}$ denotes the mean effect of dose $i$, $\beta_{i}$ denotes the differential effect of initial weight on final weight for dose $i, x_{i j}$ denotes the initial weight of calf $j$ receiving dose $i$, and $\varepsilon_{i j}$ denotes 
random error with $\varepsilon_{i j} \sim$ iid $\mathrm{N}\left(0, \sigma_{\varepsilon}^{2}\right)$.

Table 4 is a summary of the analysis of covariance results of the data presented in Table 3, assuming differential effects of the covariate (initial weight) on final weight among treatment group. The test for differential covariate effects is not significant $(\mathrm{p}=0.6594)$. Thus, an analysis of covariance assuming a common effect of initial weight on final weight for all treatment groups is considered.

Table 5 is a summary of the analysis of covariance results assuming a common effect of initial weight on final weight for all treatment groups. The test for a common covariate effect is significant $(p=0.0174)$, indicating that the initial weight of calves is important to accurately estimate the experimentation error variance. The estimate of the experimentation error variance is 282.45172 with 35 associated degrees of freedom. This represents a significant reduction in the variance estimate as compared to the results of the ANOVA given in Table 2, which does not allow for the covariate effect. Although the estimate of the experimentation error variance is reduced, the test for differences among treatment groups remains not significant $(p=0.2680)$. The least squares means reported in Table 5 are adjusted for the mean initial weight.

The significant covariate effect detected in the analysis reported in Table 5 also could be interpreted as indicating that initial weight is a nuisance source of variation that should be accommodated in the randomization scheme. Analysis of covariance techniques assume a linear relationship between the covariate and response. If the relationship between covariate and response is nonlinear, for example, analysis of covariance techniques alone may not be able to provide an accurate estimate of the experimentation error variance. A restricted randomization scheme can be useful to help control the effect of nuisance sources of variation. The following examples describe an alternative randomization scheme and analysis strategy.

\section{Randomized Complete Block Design Structure}

A randomized complete block design structure assumes that the population is not homogeneous in the sense that individuals within the population will respond differently to treatment depending on some characteristic or concomitant variable. In the above examples, initial weight proved to be related to final weight and a nuisance source of variation. However, the presented analysis of covariance assumed a linear relationship between initial and final weight. If a linear relationship cannot be assumed, a more flexible approach to accommodate a concomitant variable is to block or group the population (or the obtained sample of experimentation units) with respect to the concomitant variable. Treatment then is assigned randomly to individuals within each block. The randomization scheme is termed complete if each treatment is represented in each block at least once. Other possible concomitant or blocking variables could be location of a pen within a barn, day of week, or breed of animal.

The philosophy behind the completely randomized block design assumes that, although response to treatment may be increased or decreased corresponding to an increase or decrease of the concomitant or blocking variable, the relative magnitude of difference between treatments remains constant. Then, once the data have been adjusted through the analysis for 
block-to-block variation, the experimentation error variance can be estimated independently of block variation. Keeping block sizes as small as possible is usually recommended because large blocks tend to represent a larger portion of the total population and allow a broader range of the concomitant variable to be represented within each block. Thus, the nuisance source of variation is reintroduced into the blocks, causing the blocks to be less effective.

Table 6 is a listing of the data from the previous examples, utilizing initial weight as a blocking variable. Here, calves were ranked from smallest to largest in terms of initial weight. They then were grouped into blocks of four, with each block housed in individual pens. Treatments were assigned randomly to calves within each block, with each treatment group randomized to an experimentation unit in each block. The rationale supporting a blocked randomization using initial weight is that the estimated experimentation error variance better characterizes response in practice. The ANOVA model for this blocked design is $y_{i j}=b_{j}+\mu_{i}+\varepsilon_{i j}$ where $y_{i j}$ denotes the final weight of calf $j$ receiving dose $i, b_{j}$ denotes the effect of block $j, \mu_{i}$ denotes the mean effect of dose $i$, and $\varepsilon_{i j}$ denotes random error with $b_{j} \sim$ iid $N\left(0, \sigma_{b}^{2}\right)$ and $\varepsilon_{i j} \sim$ iid $N\left(0, \sigma_{\varepsilon}^{2}\right)$.

Table 7 is a summary of the ANOVA using the data displayed in Table 6 and incorporating the blocked design structure to accommodate pen-to-pen variation. By including a term for pen differences in the ANOVA, the response to treatment is adjusted by centering each calf's final weight by the average final weight of the corresponding pen. The remaining variation in response is then a measure of the experimentation error variance. Based on the analysis reported in Table 7 , the estimate of the experimentation error variance is 56.89532 with 27 degrees of freedom. This represents a significant reduction in the estimate of the experimentation error variance as compared to the ANOVA results reported in Table 2 , as noted by the significant test of pen variation $(p=0.0001)$. The loss of degrees of freedom associated with the estimate of the experimentation error variance as compared to the analysis reported in Table 2 is more than compensated for by the reduction in the estimate of the experimentation error variance.

If blocking is used inappropriately, the reduction of degrees of freedom can produce an inflated estimate of the experimentation error variance, thus again causing significant treatment differences to remain undetected. In this example, blocking by pen on initial weight was appropriate and effective, resulting in a significant test for treatment group differences $(p=0.0019)$. Pairwise comparisons among the least squares means for treatment response indicate that the control treatment group demonstrated a significant and lesser response to treatment as compared to the high-dose group $(p=0.0004)$. In addition, the high-dose group demonstrated a significant and greater response to treatment as compared to both the low- $(p=0.0021)$ and medium- $(p=0.0468)$ dose groups.

By blocking initial weight by pen, other sources of variation, such as pen location, could be incorporated in the statistical analysis. However, incorporating other random effects into the statistical analysis may redefine the experimentation error variance, restricting the limits of the population of inference. 


\section{Blocked Analysis of Covariance}

As discussed earlier, traditional analysis of covariance techniques assume a linear relationship between the covariate and response. If the relationship is not linear, analysis of covariance alone may not be adequate to provide an accurate estimate of the experimentation error variance. On the other hand, blocking is most effective if distinct and homogeneous groups of experimentation units can be defined.

Considering the data as presented in Table 6 , blocked by initial weight, the maximum differences in initial weight are $4.9 \mathrm{lbs}$. among the calves in pen \#9 and 4.3 lbs among the calves in pen \#10, for example. But the difference between the largest calf in pen \#9 compared to the smallest calf in pen \#10 in terms of initial weight is $0.2 \mathrm{lbs}$. This implies that, in terms of initial weight, similarity may exist between pens that cannot be accounted for by use of a blocked randomization scheme. If the blocking variable is a numeric measure, using analysis of covariance techniques in conjunction with a blocked randomization scheme may provide the best estimate of the experimentation error variance. The blocked analysis of covariance model for this design is $\mathrm{y}_{i j}=\mathrm{b}_{j}+\mu_{i}+\beta_{i} \mathrm{x}_{i j}+\varepsilon_{i j}$ where $\mathrm{y}_{i j}$ denotes the final weight of calf $j$ receiving dose $i, b_{j}$ denotes the effect of block $j, \mu_{i}$ denotes the mean effect of dose $i, \beta_{i}$ denotes the differential effect of initial weight on final weight for dose $i, x_{i j}$ denotes the initial weight of calf $j$ receiving dose $i$, and $\varepsilon_{i j}$ denotes random error with $b_{j} \sim$ iid $\mathrm{N}\left(0, \sigma_{b}^{2}\right)$ and $\varepsilon_{i j} \sim$ iid $\mathrm{N}\left(0, \sigma_{\varepsilon}^{2}\right)$.

Table 8 is a summary of the blocked analysis of covariance results of the data presented in Table 6 , incorporating both the blocked design structure as well as initial weight as a covariate. The estimate of the experimentation error variance is 47.07360 with 23 degrees of freedom. Here, differential covariate effects are detected among the treatment groups $(p=0.0488)$. This indicates that comparisons among treatment groups must be conducted for a given value of the covariate. Unless specific values of the covariate are of interest, a traditional choice is to compare treatments at the $25 \mathrm{th}$, 50th, and 75 th percentiles of the covariate. For the data in Table 6, the 25th, 50th, and 75 th percentiles of initial weight are $76.2,83.6$, and 89.6 lbs, respectively. From the results reported in Table 8 , no significant differences among treatment groups were detected at the 25th percentile of the covariate $(\mathrm{p}=0.0515)$, but significant differences among treatment groups were detected at the 50th $(p=0.0006)$ and $75 t h \quad(p=0.0003)$ percentiles of the covariate. At the 50th percentile of the covariate, significant differences were detected between the control group and both the medium- $(p=0.0301)$ and high- $(p=0.0001)$ dose groups. In addition, significant differences were detected between both the low- $(p=0.0007)$ and medium- $(p=0.0285)$ dose groups when compared to the high-dose group. At the 75th percentile of the covariate, significant differences were detected between the control group and both the medium$(\mathrm{p}=0.0019)$ and high- $(\mathrm{p}=0.0001)$ dose groups. In addition, a significant difference was detected between the low- and high-dose groups $(p=0.0028)$.

An alternative analysis strategy is to express the covariate information as deviations from the block mean initial weight. This would allow for differential covariate effects between the smallest and largest calves in each pen. The blocked analysis of covariance model for this design and analysis strategy is $\mathrm{y}_{i j}=\mathrm{b}_{j}+\mu_{i}+\delta_{i}\left(\mathrm{x}_{i j}-\overline{\mathrm{x}}_{i .}\right)+\varepsilon_{i j}$ where $\mathrm{y}_{i j}$ denotes the final weight of calf $j$ receiving dose $i, b_{j}$ denotes the effect of block $j, \mu_{i}$ 
denotes the mean effect of dose $i, \delta_{i}$ denotes the differential effect of initial weight on final weight for dose $i, x_{i j}$ denotes the initial weight of calf $j$ receiving dose $i, \bar{x}_{i}$. denotes the pen average initial weight, and $\varepsilon_{i j}$ denotes random error with $b_{j} \sim$ iid $N\left(0, \sigma_{b}^{2}\right)$ and $\varepsilon_{i j} \sim$ iid $N\left(0, \sigma_{\varepsilon}^{2}\right)$.

Table 9 is a summary of the blocked analysis of covariance results of the data presented in Table 6 , incorporating both the blocked design structure and adjusted initial weight as a covariate expressed as deviations from the pen averages. The estimate of the experimentation error variance is 53.07012 with 23 degrees of freedom. Here, differential covariate effects are not detected among the treatment groups $(p=0.1678)$. Thus, an analysis of covariance assuming a common covariate effect for all treatment groups is considered.

Table 10 is a summary of the blocked analysis of covariance results of the data presented in Table 6, assuming a common covariate effect for all treatment groups. The test for a common covariate effect is not significant $(p=0.5409)$. Deleting the common covariate term would reduce the analysis model to the blocked analysis summarized in Table 7 .

The two blocked analysis of covariance testing strategies can be combined into one analysis model. However, the analysis model will be overparameterized, resulting in some loss of information from the resulting analysis. The blocked analysis of covariance model for this design and analysis strategy is $\mathrm{y}_{i j}=\mathrm{b}_{j}+\mu_{i}+\beta_{i} \mathrm{x}_{i j}+\delta_{i}\left(\mathrm{x}_{i j}-\overline{\mathrm{x}}_{\mathrm{i}}\right)+\varepsilon_{i j}$ where $\mathrm{y}_{i j}$ denotes the final weight of calf $j$ receiving dose $i, b_{j}$ denotes the effect of block $j$, $\mu_{i}$ denotes the mean effect of dose $i, \beta_{i}$ denotes the differential effect of initial weight on final weight for dose $i, x_{i j}$ denotes the initial weight of calf $j$ receiving dose $i, \delta_{i}$ denotes the differential effect of initial weight expressed as a deviation from the block mean initial weight on final weight for dose $i, \bar{x}_{i}$. denotes the pen average initial weight, and $\varepsilon_{i j}$ denotes random error with $\mathrm{b}_{j} \sim$ iid $\mathrm{N}\left(0, \sigma_{\mathrm{b}}^{2}\right)$ and $\varepsilon_{i j} \sim$ iid $\mathrm{N}\left(0, \sigma_{\varepsilon}^{2}\right)$.

Table 11 is a summary of the combined blocked analysis of covariance results of the data presented in Table 6, assuming a differential covariate effect for all treatment groups. Neither test for differential covariate effects was significant. Removing the heterogeneous covariate effect of initial weight as a deviation from the block mean ( $\mathrm{p}=0.1499)$ reduces the analysis of covariance model to the blocked analysis of covariance summarized in Table 8 .

\section{Summary}

Drawing reliable inferences from an experiment requires not only accurate estimation of treatment response but also accurate estimation of the experimentation error variance. The estimate of the experimentation error variance provides the measure for detecting significant differences among treatment groups. The best estimate of the experimentation error variance will be independent of all other sources of variation. Highlighting potential nuisance sources of variation when designing the experiment is important to help assure successful completion.

Appropriate randomization of treatment to experimentation unit is an important part of the experimentation process. In addition to helping to remove obvious bias from the response data, randomization provides a mechanism to account for nuisance sources of variation. 
The statistical analysis must reflect the design and conduct of the study as well as characteristics of the response measure. The sequence of examples discussed in this paper demonstrate how randomization and appropriate ANOVA strategies allow for accurate estimation of the experimentation error variance.

Acknowledgment

This paper is contribution 97-470-A of the Kansas Agricultural Experiment Station, Manhattan, Kansas. 
Table 1

Completely Randomized Design Response Data: Final Weight (lbs)

\begin{tabular}{|c|c|c|c|c|c|}
\hline $\begin{array}{l}\text { Treatment } \\
\text { Group }\end{array}$ & Calf & $\begin{array}{l}\text { Final } \\
\text { Weight }\end{array}$ & $\begin{array}{l}\text { Treatment } \\
\text { Group }\end{array}$ & $\begin{array}{c}\text { Calf } \\
-\end{array}$ & $\begin{array}{l}\text { Final } \\
\text { Weight }\end{array}$ \\
\hline Control & $\begin{array}{r}3 \\
8 \\
10 \\
12 \\
14 \\
24 \\
27 \\
28 \\
32 \\
36\end{array}$ & $\begin{array}{r}74.5 \\
84.4 \\
74.8 \\
111.0 \\
61.3 \\
98.5 \\
87.2 \\
98.0 \\
72.4 \\
87.5\end{array}$ & Medium & $\begin{array}{l}5 \\
15 \\
21 \\
23 \\
25 \\
30 \\
33 \\
38 \\
39 \\
40\end{array}$ & $\begin{array}{r}69.6 \\
67.6 \\
124.4 \\
111.4 \\
82.4 \\
106.7 \\
78.7 \\
77.3 \\
107.1 \\
91.8\end{array}$ \\
\hline Low & $\begin{array}{r}2 \\
4 \\
6 \\
7 \\
11 \\
13 \\
19 \\
29 \\
34 \\
37\end{array}$ & $\begin{array}{r}116.4 \\
71.8 \\
91.6 \\
76.0 \\
84.5 \\
88.7 \\
109.1 \\
76.6 \\
73.6 \\
84.1\end{array}$ & High & $\begin{array}{r}1 \\
9 \\
16 \\
17 \\
18 \\
20 \\
22 \\
26 \\
31 \\
35\end{array}$ & $\begin{array}{r}94.4 \\
72.5 \\
69.4 \\
127.2 \\
85.2 \\
103.8 \\
126.8 \\
83.6 \\
101.6 \\
122.8\end{array}$ \\
\hline
\end{tabular}

Table 2

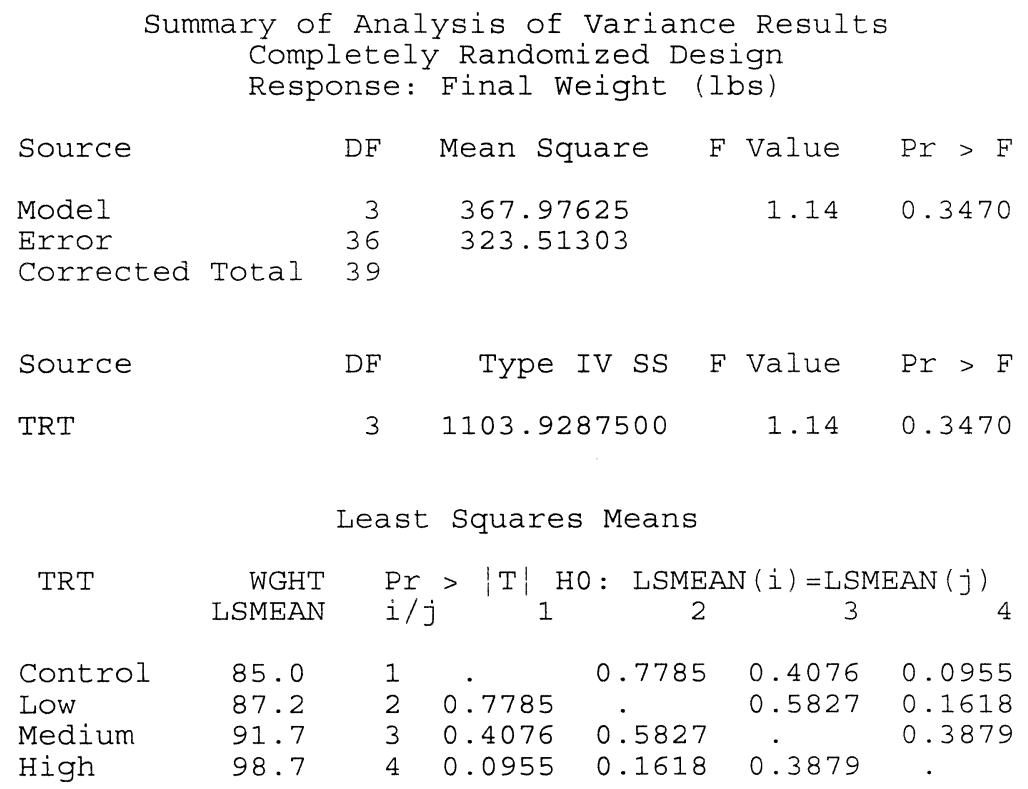


Table 3

Completely Randomized Design Response Data: Final Weight (lbs)

Covariate: Initial weight (lbs)

\begin{tabular}{|c|c|c|c|c|c|c|c|}
\hline $\begin{array}{l}\text { Treatment } \\
\text { Group }\end{array}$ & Calf & $\begin{array}{l}\text { Initial } \\
\text { Weight }\end{array}$ & $\begin{array}{l}\text { Final } \\
\text { Weight }\end{array}$ & $\begin{array}{l}\text { Treatment } \\
\text { Group }\end{array}$ & $\begin{array}{c}\text { Calf } \\
-.--\end{array}$ & $\begin{array}{l}\text { Initial } \\
\text { Weight }\end{array}$ & $\begin{array}{l}\text { Final } \\
\text { Weight }\end{array}$ \\
\hline Control & $\begin{array}{r}3 \\
8 \\
10 \\
12 \\
14 \\
24 \\
27 \\
28 \\
32 \\
36\end{array}$ & $\begin{array}{l}89.3 \\
72.9 \\
95.0 \\
75.9 \\
73.4 \\
84.0 \\
88.4 \\
99.0 \\
80.0 \\
78.6\end{array}$ & $\begin{array}{r}74.5 \\
84.4 \\
74.8 \\
111.0 \\
61.3 \\
98.5 \\
87.2 \\
98.0 \\
72.4 \\
87.5\end{array}$ & Medium & $\begin{array}{r}5 \\
15 \\
21 \\
23 \\
25 \\
30 \\
33 \\
38 \\
39 \\
40\end{array}$ & $\begin{array}{l}71.9 \\
73.6 \\
95.2 \\
87.0 \\
92.9 \\
76.2 \\
89.7 \\
82.4 \\
87.2 \\
78.1\end{array}$ & $\begin{array}{r}69.6 \\
67.6 \\
124.4 \\
111.4 \\
82.4 \\
106.7 \\
78.7 \\
77.3 \\
107.1 \\
91.8\end{array}$ \\
\hline Low & $\begin{array}{r}2 \\
4 \\
6 \\
7 \\
11 \\
13 \\
19 \\
29 \\
34 \\
37\end{array}$ & $\begin{array}{l}99.0 \\
72.8 \\
76.2 \\
74.9 \\
77.7 \\
87.1 \\
83.9 \\
93.2 \\
89.7 \\
83.1\end{array}$ & $\begin{array}{r}116.4 \\
71.8 \\
91.6 \\
76.0 \\
84.5 \\
88.7 \\
109.1 \\
76.6 \\
73.6 \\
84.1\end{array}$ & High & $\begin{array}{r}1 \\
9 \\
16 \\
17 \\
18 \\
20 \\
22 \\
26 \\
31 \\
35\end{array}$ & $\begin{array}{l}89.5 \\
70.6 \\
73.2 \\
76.4 \\
90.1 \\
76.5 \\
99.5 \\
83.3 \\
88.0 \\
85.8\end{array}$ & $\begin{array}{r}94.4 \\
72.5 \\
69.4 \\
127.2 \\
85.2 \\
103.8 \\
126.8 \\
83.6 \\
101.6 \\
122.8\end{array}$ \\
\hline
\end{tabular}

Table 4

Summary of Analysis of Covariance Results

Assuming Differential Covariate Effects

Completely Randomized Design

Response: Final Weight (Ibs)

Covariate: Initial Weight (lbs)

$\begin{array}{lrrrr}\text { Source } & \text { DF } & \text { Mean Square } & \text { F Value } & \text { Pr }>\text { F } \\ \text { Model } & 7 & 477.08185 & 1.62 & 0.1649 \\ \begin{array}{l}\text { Error } \\ \text { Corrected Total }\end{array} & 39 & 294.08828 & & \\ & & & & \\ \text { Source } & \text { DF } & \text { Type IV.SS } & \text { F Value } & \text { Pr }>\text { F } \\ \text { TRT } & 3 & 367.01801528 & 0.42 & 0.7427 \\ \text { INT_WGHT } & 1 & 1834.58290525 & 6.24 & 0.0178 \\ \text { INT_WGHT*TRT } & 3 & 474.98521765 & 0.54 & 0.6594\end{array}$


Table 5

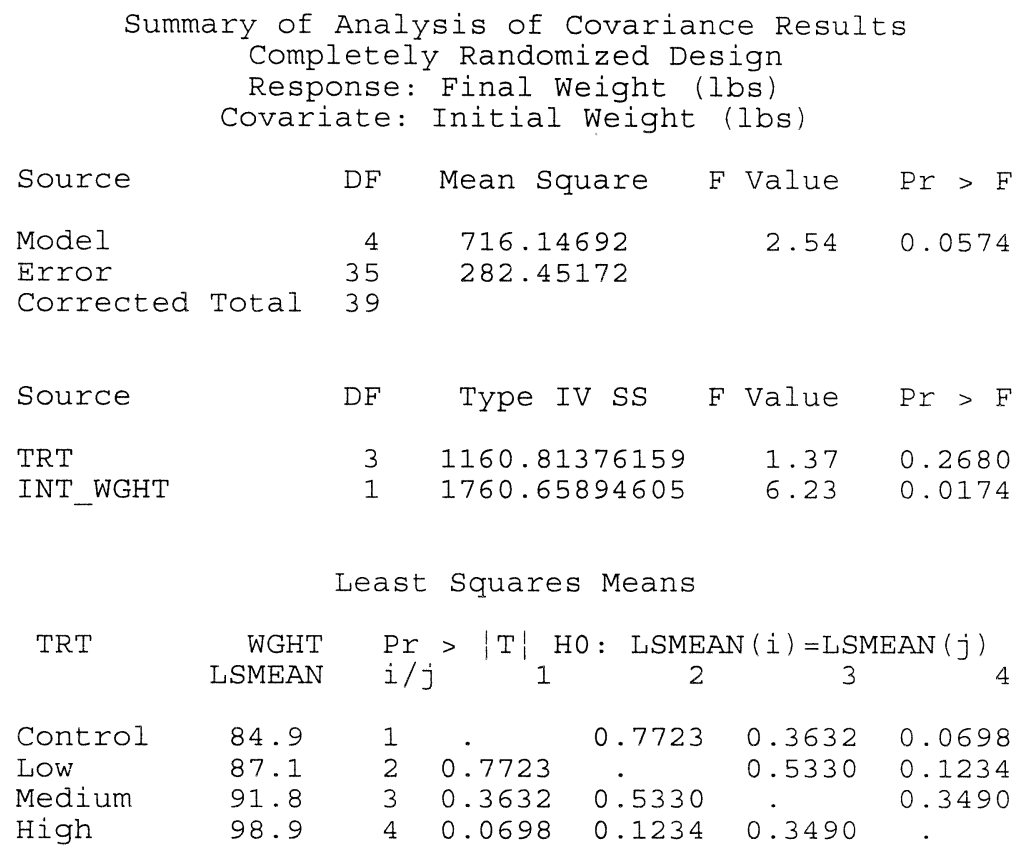

Table 6

\begin{tabular}{|c|c|c|c|c|c|c|c|c|c|}
\hline Pen & $\begin{array}{c}\text { Treatment } \\
\text { Group }\end{array}$ & Calf & $\begin{array}{l}\text { Initial } \\
\text { Weight }\end{array}$ & $\begin{array}{l}\text { Final } \\
\text { Weight }\end{array}$ & $\begin{array}{l}\text { Pen } \\
--\end{array}$ & $\begin{array}{l}\text { Treatment } \\
\text { Group }\end{array}$ & Calf & $\begin{array}{l}\text { Initial } \\
\text { Weight }\end{array}$ & $\begin{array}{l}\text { Final } \\
\text { Weight }\end{array}$ \\
\hline 1 & $\begin{array}{l}\text { High } \\
\text { Medium } \\
\text { Low } \\
\text { Control }\end{array}$ & $\begin{array}{l}9 \\
5 \\
4 \\
8\end{array}$ & $\begin{array}{l}70.6 \\
71.9 \\
72.8 \\
72.9\end{array}$ & $\begin{array}{l}72.5 \\
69.6 \\
71.8 \\
84.4\end{array}$ & 6 & $\begin{array}{l}\text { Low } \\
\text { Control } \\
\text { High } \\
\text { Medium }\end{array}$ & $\begin{array}{l}19 \\
24 \\
35 \\
23\end{array}$ & $\begin{array}{l}83.9 \\
84.0 \\
85.8 \\
87.0\end{array}$ & $\begin{array}{r}109.1 \\
98.5 \\
122.8 \\
111.4\end{array}$ \\
\hline 2 & $\begin{array}{l}\text { High } \\
\text { Control } \\
\text { Medium } \\
\text { Low }\end{array}$ & $\begin{array}{r}16 \\
14 \\
15 \\
7\end{array}$ & $\begin{array}{l}73.2 \\
73.4 \\
73.6 \\
74.9\end{array}$ & $\begin{array}{l}69.4 \\
61.3 \\
67.6 \\
76.0\end{array}$ & 7 & $\begin{array}{l}\text { Low } \\
\text { Medium } \\
\text { High } \\
\text { Control }\end{array}$ & $\begin{array}{l}13 \\
39 \\
31 \\
27\end{array}$ & $\begin{array}{l}87.1 \\
87.2 \\
88.0 \\
88.4\end{array}$ & $\begin{array}{r}88.7 \\
107.1 \\
101.6 \\
87.2\end{array}$ \\
\hline 3 & $\begin{array}{l}\text { Control } \\
\text { Low } \\
\text { Medium } \\
\text { High }\end{array}$ & $\begin{array}{r}12 \\
6 \\
30 \\
17\end{array}$ & $\begin{array}{l}75.9 \\
76.2 \\
76.2 \\
76.4\end{array}$ & $\begin{array}{r}111.0 \\
91.6 \\
106.7 \\
127.2\end{array}$ & 8 & $\begin{array}{l}\text { Control } \\
\text { High } \\
\text { Low } \\
\text { Medium }\end{array}$ & $\begin{array}{r}3 \\
1 \\
34 \\
33\end{array}$ & $\begin{array}{l}89.3 \\
89.5 \\
89.7 \\
89.7\end{array}$ & $\begin{array}{l}74.5 \\
94.4 \\
73.6 \\
78.7\end{array}$ \\
\hline 4 & $\begin{array}{l}\text { High } \\
\text { Low } \\
\text { Medium } \\
\text { Control }\end{array}$ & $\begin{array}{l}20 \\
11 \\
40 \\
36\end{array}$ & $\begin{array}{l}76.5 \\
77.7 \\
78.1 \\
78.6\end{array}$ & $\begin{array}{r}103.8 \\
84.5 \\
91.8 \\
87.5\end{array}$ & 9 & $\begin{array}{l}\text { High } \\
\text { Medium } \\
\text { Low } \\
\text { Control }\end{array}$ & $\begin{array}{l}18 \\
25 \\
29 \\
10\end{array}$ & $\begin{array}{l}90.1 \\
92.9 \\
93.2 \\
95.0\end{array}$ & $\begin{array}{l}85.2 \\
82.4 \\
76.6 \\
74.8\end{array}$ \\
\hline 5 & $\begin{array}{l}\text { Control } \\
\text { Medium } \\
\text { Low } \\
\text { High }\end{array}$ & $\begin{array}{l}32 \\
38 \\
37 \\
26\end{array}$ & $\begin{array}{l}80.0 \\
82.4 \\
83.1 \\
83.3\end{array}$ & $\begin{array}{l}72.4 \\
77.3 \\
84.1 \\
83.6\end{array}$ & 10 & $\begin{array}{l}\text { Medium } \\
\text { Control } \\
\text { Low } \\
\text { High }\end{array}$ & $\begin{array}{r}21 \\
28 \\
2 \\
22\end{array}$ & $\begin{array}{l}95.2 \\
99.0 \\
99.0 \\
99.5\end{array}$ & $\begin{array}{r}124.4 \\
98.0 \\
116.4 \\
126.8\end{array}$ \\
\hline
\end{tabular}


Table 7

Summary of Analysis of Variance Results

Randomized Complete Block Design

Response: Final Weight (lbs)

Blocking Variable: Initial Weight (lbs)

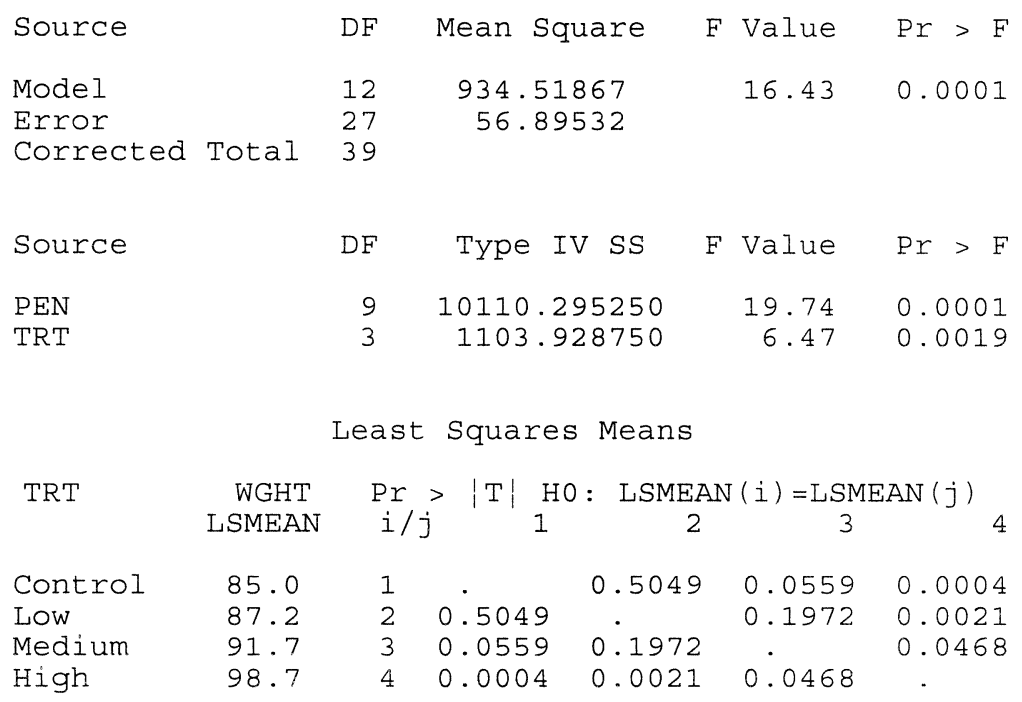

Table 8

Summary of Analysis of Covariance Results Assuming Differential Covariate Effects

Randomized Complete Block Design Response: Final Weight (lbs)

Blocking Variable: Initial weight (Ibs)

Covariate: Initial Weight (lbs)

\begin{tabular}{|c|c|c|c|c|c|c|}
\hline Source & $\mathrm{DF}$ & \multicolumn{2}{|c|}{ Mean Square } & $\mathrm{F}$ & Value & $\operatorname{Pr}>\mathrm{F}$ \\
\hline Model & 16 & \multirow{2}{*}{\multicolumn{2}{|c|}{$\begin{array}{r}729.23157 \\
47.07360\end{array}$}} & & \multirow[t]{3}{*}{15.49} & \multirow[t]{3}{*}{0.0001} \\
\hline Error & 23 & & & & & \\
\hline Corrected Total & 39 & & & & & \\
\hline Source & DF & \multicolumn{3}{|c|}{ Type IV SS } & Value & Pr $>$ \\
\hline PEN & 9 & \multicolumn{3}{|c|}{8328.13213948} & 19.66 & 0.000 \\
\hline TRT & 3 & \multicolumn{3}{|c|}{348.39243018} & 2.47 & 0.087 \\
\hline INT WGHT & 1 & \multicolumn{3}{|c|}{83.93649451} & 1.78 & 0.194 \\
\hline INT_WGHT*TRT & 3 & \multicolumn{3}{|c|}{431.12898534} & 3.05 & 0.048 \\
\hline \multicolumn{2}{|l|}{ Contrast } & $\mathrm{DF}$ & Contrast & SS & F Value & $\operatorname{Pr}>$ \\
\hline \multicolumn{2}{|c|}{ TRT at INT_WGHT $=76.2$} & 3 & \multicolumn{2}{|c|}{423.49480} & 3.00 & 0.05 \\
\hline \multicolumn{2}{|c|}{ TRT at INT_WGHT $=83.6$} & 3 & \multicolumn{2}{|c|}{1181.92973} & 8.37 & 0.0 \\
\hline CRT at INT_WGH & 9.6 & 3 & 1342.181 & & 9.50 & 0.0 \\
\hline
\end{tabular}


Table 8 , continued

Summary of Analysis of Covariance Results Randomized Complete Block Design

Assuming Differential Covariate Effects Response: Final Weight (lbs.)

Blocking Variable: Initial Weight (lbs.)

Covariate: Initial Weight (lbs.)

Least Squares Means at INT_WGHT $=76.2$

TRT

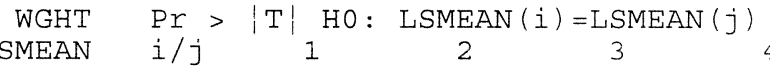

Control

Low

79.15

75.92

1

.

Medium

78.07

0.4465

0.4465

0.7968

0.0491

$\mathrm{High}$

87.55

0.7968

0.0491

0.6136

0.6136

0.0109

Least Squares Means at INT_WGHT $=83.6$

TRT

$$
\begin{array}{rc|ccc}
\text { WGHT } & \operatorname{Pr}>|T| & \text { HO: } & \operatorname{LSMEAN}(i)=\operatorname{LSMEAN}(j) \\
\text { LSMEAN } & i / j & 1 & 2 & 3
\end{array}
$$

Control

Low

Medium

84.92

High

87.00

0.5051
0.0301

0.5051

0.0301

0.0001

92.04

0.0001

0.1168

0 .

0.0007

0.0285

0.0285

Least Squares Means at INT_WGHT $=89.6$

TRT

\begin{tabular}{rl|ccc} 
WGHT & $\operatorname{Pr}>|\mathrm{T}|$ & $\mathrm{HO}:$ & $\operatorname{LSMEAN}(i)=\operatorname{LSMEAN}(j)$ \\
LSMEAN & $i / j$ & 1 & 2 & 3
\end{tabular}

Control

Low

89.60

1

.

0.1035

0.0019

0.0001

Medium

95.98

103.37

20.1035

30.0019

0.0712

0.0712

0.0028

High

108.68

0.0001

0.0028

0.186

0.1869

Table 9

Summary of Analysis of Covariance Results Randomized Complete Block Design

Assuming Differential Covariate Effects Response: Final Weight (lbs.)

Blocking Variables: Initial Weight (lbs.) Covariate: Deviation from Pen Mean

$\begin{array}{lrrrr}\text { Source } & \text { DF } & \text { Mean Square } & \text { F Value } & \text { Pr }>F \\ \text { Model } & 16 & 720.6115614 & 13.58 & 0.0001 \\ \text { Error } & 23 & 53.0701203 & & \\ \text { Corrected Total } & 39 & & & \\ & & & & \\ \text { Source } & \text { DF } & \text { Type IV SS } & \text { F Value } & \text { Pr }>\text { F } \\ \text { PEN } & 9 & 8615.80414215 & 18.04 & 0.0001 \\ \text { TRT } & 3 & 1257.87363830 & 7.90 & 0.0008 \\ \text { D_WGHT } & 1 & 88.99518847 & 1.68 & 0.2082 \\ \text { D_WGHT*TRT } & 3 & 293.20891440 & 1.84 & 0.1678\end{array}$


Table 10

Summary of Analysis of Covariance Results

Randomized Complete Block Design

Assuming Common Covariate Effects Response: Final Weight (lbs.)

Blocking Variables: Initial Weight (Ibs.)

Covariate: Deviation from Pen Mean

$\begin{array}{lrrrr}\text { Source } & \text { DF } & \text { Mean Square } & \text { F Value } & \text { Pr }>F \\ \text { Model } & 13 & 864.3520052 & 14.85 & 0.0001 \\ \begin{array}{l}\text { Error } \\ \text { Corrected Total }\end{array} & 26 & 58.2239108 & & \\ & 39 & & & \\ \text { Source } & \text { DF } & \text { Type IV SS } & \text { F Value } & \text { Pr }>\text { F } \\ & & & & \\ \text { PEN } & 9 & 10110.2952500 & 19.29 & 0.0001 \\ \text { TRT } & 3 & 1126.0465310 & 6.45 & 0.0021 \\ \text { D_WGHT } & 1 & 22.3520678 & 0.38 & 0.5409\end{array}$

Least Squares Means

$\begin{array}{rcccc}\text { WGHT } & \operatorname{Pr}>|\mathrm{T}| \mathrm{HO}: \operatorname{LSMEAN}(i)=\operatorname{LSMEAN}(j) \\ \text { LSMEAN } & i / j & 1 & 2\end{array}$

$\begin{array}{llllllll}\text { Control } & 84.88 & 1 & . & 0.5245 & 0.0542 & 0.0004\end{array}$

$\begin{array}{lllllll}\text { Low } & 87.08 & 2 & 0.5245 & . & 0.1830 & 0.0021\end{array}$

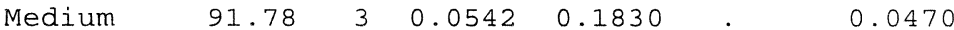

$\begin{array}{lllllll}\text { High } & 98.90 & 4 & 0.0004 & 0.0021 & 0.0470\end{array}$

Table 11

Summary of Analysis of Covariance Results

Randomized Complete Block Design

Assuming Differential Covariate Effects

Response: Final Weight (lbs.)

Blocking Variables: Initial weight (lbs.)

Covariates: Initial Weight (lbs.)

Deviation from Pen Mean

$\begin{array}{lrrrr}\text { Source } & \text { DF } & \text { Mean Square } & \text { F Value } & \text { Pr }>F \\ \text { Model } & 19 & 627.1230898 & 15.02 & 0.0001 \\ \begin{array}{l}\text { Error } \\ \text { Corrected Total }\end{array} & 20 & 41.7529521 & & \\ & 39 & & & \\ \text { Source } & \text { DF } & \text { Type IV SS } & \text { F Value } & \text { Pr }>\text { F } \\ & & & & \\ \text { PEN } & 8 & 7606.16670019 & 22.77 & 0.0001 \\ \text { TRT } & 3 & 321.25036228 & 2.56 & 0.0834 \\ \text { INT_WGHT*TRT } & 3 & 385.55372483 & 3.08 & 0.0510 \\ \text { D_WGHT*TRT } & 3 & 247.63365389 & 1.98 & 0.1499\end{array}$

Least Squares Means

TRT

\begin{tabular}{rc|cc} 
WGHT & $\operatorname{Pr}>|T|$ HO: & $\operatorname{LSMEAN}(i)=\underset{1}{\operatorname{LSMEAN}}(j)$ \\
LSMEAN & $i / j$ & 1 & 2
\end{tabular}

Control

84.60

Low

Medium

85.58

91.39

High

Non-est

1
2
3
4

0.7465
0.0303

0.7465

0.0303

.0 .0669

0.0669 . 
Figure 1

Completely Randomized Design

Final Weight of Calves by Treatment Group

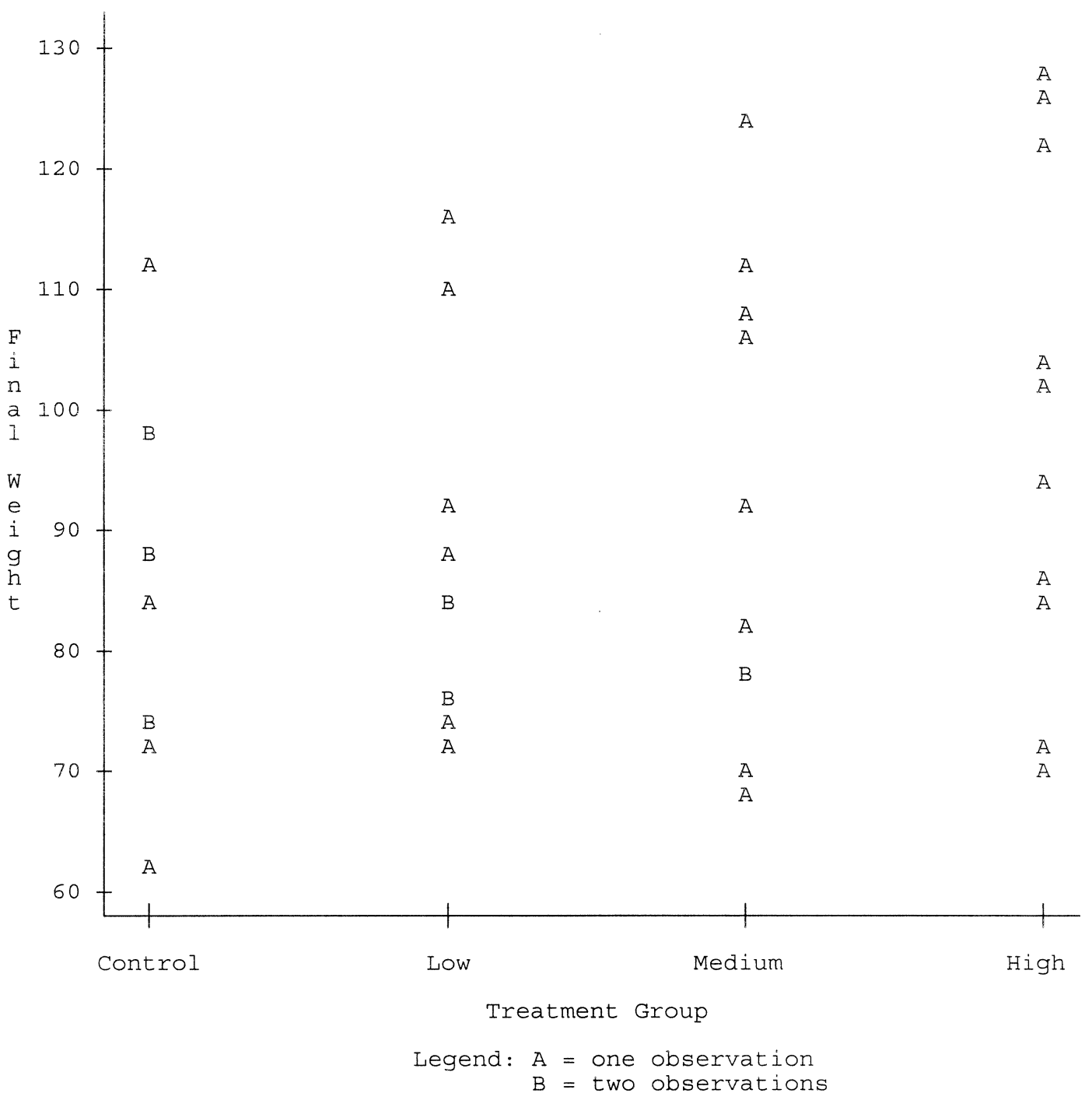

